\title{
Comparative study on the mental wellbeing among regularly meditating and non-meditating health care personnel in Sri Lanka
}

\author{
Wasantha Gunathunga ${ }^{1}$, Oshadi Jayakody ${ }^{2}$, Larrissa Bartlett ${ }^{2}$, Ishanka Munugoda ${ }^{2}$, Champa \\ Kumudini Gunathunga ${ }^{3}$
}

${ }^{1}$ Department of Community Medicine, Faculty of Medicine, University of Colombo, Sri Lanka; ${ }^{2}$ Menzies Institute for Medical Research, University of Tasmania, Australia; ${ }^{3}$ Colombo North Teaching Hospital, Ragama, Sri Lanka.

*Correspondence: wasantg@commed.cmb.ac.lk

https://orcid.org/0000-0003-0818-6279

Received on: 7 May 2019

Accepted on: 29 July 2019

\begin{abstract}
Introduction: Meditation holds the potential for reducing occupation related stress. However, the current evidence base is largely limited to studies from the western countries with insufficient assessment of performance outcomes.

Objectives: To examine the differences in the level of mental wellbeing and depression between regularly meditating and non-meditating health care personnel primarily from a Buddhist population

Methods: This study was a descriptive comparative study among health care workers $(n=60)$, exploring the moderating effect of having participated in a structured Vipassana informed mindfulness mediation programme. Data were collected after six months of meditation following the first training session. Mental wellbeing and depression were assessed using Primary Mental Health Questionnaire (PMHQ) and Centre for Epidemiological Studies-Depression scale (CES-D) respectively. Independent sample t Test and Wilcoxon Rank Sum Test were performed to determine the differences in the status of metal wellbeing and level of depression between regular meditators and non-meditators.

Results: Regular meditators showed higher levels of mental wellbeing compared to non-meditators, indicated by a significant difference in PMHQ values ( $\mathrm{p}=0.001$ ); and significantly lower depression levels according to the CES-D scores $(\mathrm{p}<0.01)$.

Conclusions: Our findings suggest that Vipassana informed mindfulness meditation is associated with improved mental wellbeing and may have profound practical implications among health care professionals. This method with its simple and low-cost approach needs to be tested in other professional groups, to increase the generalizability and applicability
\end{abstract}

Key words: Vipassana informed mediation, regular meditators, health care personnel, mindfulness, mental wellbeing 


\section{Introduction}

Mental wellbeing is a state which enables individuals to realize their abilities, cope with the normal stresses of life and work productively to contribute to their communities (1). It is considered vital for the physical and social wellbeing of an individual (1). Meditation is a practice of virtually every religion in the world (2-3). Buddhist meditation, with three basic forms as attention, mindfulness and compassion has been practised globally over centuries (2). Sri Lanka is predominantly a Buddhist country with a history spanning over two and a half millennia (4). During this period, the Sri Lankan culture has been moulded by wisdom inculcated through Buddhist values, such as compassion, universal impermanence and causality taught through formal Vipassana meditation (5).

Positive effects of training the mind with meditation on mental, physical and overall wellbeing have long been known (2). Introducing mediation to western societies has resulted in similar outcomes, in both clinical (6) and healthy populations (7), despite the absence of Buddhist foundations. Meditation is studied across a wide spectrum of diseases including cancer (8-9), asthma, multiple sclerosis (10) and psychological disorders $(3,6,11-14)$ has proven to be a pragmatic tool for reducing stress and enhancing health related quality of life $(3,8,12,15-16)$. These benefits are seen in more objective measures of neurological and biological markers of cognition, emotional reactivity and stress (7). At the functional level, meditation improves cognitive performance (16) and reduces stress with reported consequential potential of promoting human cellular longevity (17).

Health care professionals work in stressful environments characterized by high emotional demands and low levels of control (18). Maintaining patient focus and compassion is integral in their daily duties, yet employees faced with higher levels of stress can easily become emotionally exhausted and often display symptoms of burnout (19). This results in reduced capacity to provide quality care and can be costly for employers through health-related lost productive time (20). For these reasons, workplaces are increasingly seeking interventions that can support employees to prevent burnout and other stress-related health problems.

Mindfulness training delivered at work has been shown as effective in reducing stress, improving mental health and wellbeing $(13,21-26)$. Also, the current evidence base comes from a limited number of studies, mostly from the USA. No studies have investigated the effects of mindfulness practices for working people in the context of Buddhist culture. Most of the trials are also limited by being inadequately powered or with lack of controlling for placebo effects $(15,27-29)$.

The aim of this study was to examine the differences in the levels of mental wellbeing and depression between regularly meditating and non-meditating health care personnel drawn from a predominant Buddhist population. We hypothesized that regular meditation is associated with enhanced levels of mental wellbeing and reduced levels of depression. If our hypothesis is supported, the findings would suggest that regular practice adds incremental benefit beyond general Buddhist cultural socialization.

\section{Methods}

This was a cross-sectional study among health care personnel of varying professions recruited from seven offices of medical officers of health $(\mathrm{MOH})$ in Colombo District, Sri Lanka. Six months prior to the study in August 2016, we introduced distinct Vipassanainformed mindfulness meditation, which is different to meditation practices that are becoming increasingly common in the western societies, such as transcendental meditation and secular Mindfulness Based Stress Reduction (MBSR) (30). The focus of Vipassanainformed mindfulness meditation is on cultivating discipline, mindfulness and wisdom, and this underpins the foundational practices described in Dhamma (31). The population studied was a primarily Buddhist cohort, thus we believed that the choice of Vipassana meditation was appropriate for the cultural setting in which it was delivered. The meditation programme was conducted over three months. It consisted of two onehour sessions, one month apart, delivered by a trained facilitator with more than 10 years of experience in teaching Vipassana meditation. Initially, 150 participants were enrolled in the programme. Opening sessions were comprised of a lecture and discussion on the effectiveness of meditation, following which participants were guided through the meditation practice. At the end of these sessions', participants were given time to discuss their experience and ask questions. 
The meditation practice was modelled into three steps. Step one included physical discipline of sitting motionless for a predetermined period of time. The second step was a body scan with the mind as a probe for scanning the body. Meditator steers the attention through a pre-identified number of 25 body parts (from head through face, trunk, right lower limb and left lower limb to the toes of the left leg and returning to the head to re-start the cycle). A verse on "loving kindness", contemplated on each body part scanned, was used as a tool for letting go. This step also included acknowledging any sensation in different regions of the body, such as pain and, letting go of those with resulting mental quietude. In the third step, building on the previous two steps, meditator gets into a comfortable state of minimal stress and an insight into the occurrence of thoughts, and source and cessation of such thoughts. This method of meditation is a modified version of Vipassana meditation originally expounded by The Buddha (32). Participants were instructed to continue the meditation practice for 15-20 minutes each day at home. Adherence was encouraged and reported in daily meditation diaries (See Table 1).

All those who participated in the mediation programme were considered eligible for the study. They were recruited into two groups: 1) a group of regular meditators and 2) a group of age, sex and occupation matched non-meditators from the same study settings. Those who practised other methods of meditation concurrently were excluded.

Sample size of 35 participants was required in each group (with a power of $80 \%$ and Alpha error of $5 \%$ ) to detect $20 \%$ achieving happiness score of more than 5 on a 10-point scale (P1) among the comparison group and $50 \%$ meditators to achieve the same level (33). In the seven $\mathrm{MOH}$ offices, there were 30 health care professionals aged 25-60 meditating on a daily basis and were recruited as regular meditators. A similar number of age and occupation matched nonmeditators were conveniently selected from the same study settings for the non-meditation group. All participants provided informed consent upon study enrolment. Data were collected six months after the first meditation training session by a data collector visiting the participants at their workplaces. Ethical clearance was obtained from the Ethics Review Committee, Faculty of Medicine, University of Colombo, Sri Lanka.
PMHQ was used to assess the level of mental wellbeing, of which the validity and internal consistency are reported to be satisfactory and reported in detail elsewhere (34). It is a 11-item scale designed to measure the primary aspects of mental wellbeing in apparently healthy individuals by rating adjective like statements (e.g. What is your level of satisfaction about the money you have with you to spend?). Each statement is ranked on a 10-point Likert scale. PMHQ is comprised of five subscales, namely satisfaction, compassion, worries, perception about improving mind and previous attempts at improving mind (34). The sum of the values was used in the final analysis to determine the level of mental wellbeing.

Depression levels among the participants were measured using Centre for Epidemiological StudiesDepression scale (CES-D) consisting of 20 questions appraising depression. This scale has been proven to have high validity and reliability. On a 4-point Likert scale, subjects are requested to rate statements (E.g. I felt happy or I felt depressed) related to last week. The scores range from 0 to 60 . Higher scores denote higher depression levels (35).

\section{Data analysis}

Statistical analyses were done using STATA Statistical Software Package (version 14.2). Descriptive characteristics were summarized with means and standard deviation (SD) or frequencies and proportions, as appropriate. The significant differences in the status of mental wellbeing and level of depression between regular meditators and non-meditators were determined by Independent Sample T-Test and Wilcoxon Rank Sum Test. Similar differences in relation to the subscales of PMHQ were also tested with Independent Sample T-Test (Levels of satisfaction, compassion and worries) and Wilcoxon Rank Sum Test (perception about improving mind and previous attempts at improving mind) after assessing the normality of their distribution. $\mathrm{P}$ values of less than 0.05 were considered significant.

\section{Results}

Descriptive characteristics of the study population are shown in Table 2. A total of 60 health care personnel $(n=30$ meditators; $n=30$ non meditators) were included 
in the study. The majority of participants were medical professionals $(n=36 ; 60 \%)$ and female $(n=47 ; 78.33 \%)$. Average age was $45.6(\mathrm{SD}=9.1)$ years among meditators and $46.0(\mathrm{SD}=8.3)$ among non-meditators.

There was a significant difference in total PMHQ scores $(p=0.0003)$ and satisfaction subscale $(t=0.03$, $\mathrm{p}=0.002$ ) between regular meditators and nonmeditators, indicating higher levels of overall mental wellbeing and satisfaction among meditators. Scores in the compassion subscale was higher among regular meditators but the difference was not statistically significant $(p>0.05)$, and worries were shown to be more common among meditators, though not significant $(\mathrm{p}>0.05)$ (Table 3$)$.

Two of the five subscales of PMHQ, perception about improving mind ( $z=2.769 ; \mathrm{p}<0.01$, Mann Whitney test) and the attempts to improve mind $(\mathrm{z}=3.39 ; \mathrm{p}<0.01$, Mann Whitney test) were significantly higher among meditating than non-meditating groups. CES-D $(p<0.01)$ values between regular meditators were significantly lower, indicating lower depression levels compared to non-meditators.

Table 1. The structured meditation programme

\begin{tabular}{|c|c|}
\hline Opening session & $\begin{array}{l}\text { - A lecture on meditation, detailed explanation on } \\
\text { benefits for personal and professional life and an } \\
\text { open group discussion. } \\
\text { - Introduction to the meditation programme } \\
\text { procedures } \\
\text { - Guided meditation practice } \\
\text { - Group discussion }\end{array}$ \\
\hline Weeks $1,2,3$ & $\begin{array}{l}\text { - Daily practice of the meditation learned in the } \\
\text { Opening session (15-20 minutes) } \\
\text { - Record their experience, difficulties and other } \\
\text { concerns in a daily journal. }\end{array}$ \\
\hline Week 4 (Session 2) & $\begin{array}{l}\text { - Guided meditation practice } \\
\text { - Group discussion and sharing of the meditation } \\
\text { experience of participants }\end{array}$ \\
\hline Weeks $5,6,7$ & As for Weeks 1, 2 and 3 \\
\hline Week 8 (Session 3) & As for session 2 (Week 4) \\
\hline Weeks $9,10,11$ & As for Weeks 5, 6 and 7 \\
\hline Week 12 (Session 4) & As for session 3 (Week 8) \\
\hline
\end{tabular}


Table 2. Characteristics of the participants

\begin{tabular}{|c|c|c|c|c|}
\hline \multirow{3}{*}{$\begin{array}{l}\text { Characteristics } \\
\text { Age, mean (SD) }\end{array}$} & \multicolumn{4}{|c|}{ No. $(\%)$} \\
\hline & \multicolumn{2}{|c|}{$\begin{array}{l}\text { Meditators } \\
\quad(n=30)\end{array}$} & \multicolumn{2}{|c|}{$\begin{array}{c}\text { Non-meditators } \\
(\mathrm{n}=\mathbf{3 0})\end{array}$} \\
\hline & 45.6 & $(9.1)$ & 46.0 & $(8.3)$ \\
\hline Female, no. $(\%)$ & 24 & $(80.0)$ & 23 & $(76.7)$ \\
\hline \multicolumn{5}{|l|}{ Occupation, no. (\%) } \\
\hline Medical personnel & 17 & $(56.7)$ & 19 & $(63.3)$ \\
\hline Nursing personnel & 9 & $(30.0)$ & 9 & $(30.0)$ \\
\hline Other health care personnel & 4 & $(13.3)$ & 2 & $(6.7)$ \\
\hline Buddhist, no. (\%) & 29 & $(96.7)$ & 28 & $(93.3)$ \\
\hline Married, no. (\%) & 30 & $(100)$ & 29 & $(96.7)$ \\
\hline
\end{tabular}

Table 3. Levels of mental well-being among meditators and non-meditators

\begin{tabular}{|c|c|c|c|c|c|}
\hline \multirow[t]{2}{*}{ Outcome measure } & \multicolumn{4}{|c|}{ Mean $(95 \%$ CI) } & \multirow[t]{2}{*}{ t value; } \\
\hline & & $\begin{array}{l}\text { tators } \\
\text { 30) }\end{array}$ & & $\begin{array}{l}\text { ditators } \\
\text { 30) }\end{array}$ & \\
\hline $\begin{array}{l}\text { Level of mental well-being } \\
\text { (Total PMHQ) }\end{array}$ & 0.78 & $(0.74-0.82)$ & 0.68 & $(0.64-0.72)$ & $3.36 ; 0.0003$ \\
\hline Level of satisfaction & 0.82 & $(0.77-0.88)$ & 0.71 & $(0.65-0.76)$ & $3.03 ; 0.002$ \\
\hline Level of compassion & 0.76 & $(0.70-0.81)$ & 0.71 & $(0.65-0.79)$ & $0.88 ; 0.19$ \\
\hline Worries & 0.72 & $(0.67-0.77)$ & 0.70 & $(0.63-0.76)$ & $0.5 ; 0.3$ \\
\hline
\end{tabular}

\section{Discussion}

Data from this cross-sectional study suggest enhanced levels of mental wellbeing and decreased levels of depression among regular meditators. The primary findings were higher values in PMHQ and lower values in CES-D among health care professionals who meditate on a regular basis, compared to nonmeditators.

While several studies have evaluated the effectiveness of meditation in reducing occupational stress in professional groups such as schoolteachers $(12,16)$ or health care workers $(14-15,17)$, none have previously investigated effects for people from a Buddhist culture. Our sample included health care personnel who belong to a primarily Buddhist population, half of whom indicated they were inclined to engage in meditation, and half who were not. We observed lower depression levels among regular meditators, six months after commencing the programme. These findings are in line with previous studies that have investigated the impact of meditation on depression, stress (14-15) and 
burnout (17). Most of the studies are generally in agreement that meditation could be effective in reducing levels of stress and depression among employees despite the variability in the meditation techniques that have been used $(14-15,17)$. The most evidenced programmes include transcendental meditation, settling the mind into a free-of-content, silent status of awareness using a mantra (36) and a standardized, secular mindfulness-based training program in which the focus is on the internal and external stimuli at the present moment (37). In contrast, our technique was based on Vipassana mindfulness meditation. This is deeply informed by the Buddhist foundational practices on cultivating discipline, mindfulness, and wisdom thus boarder in focus than transcendental meditation and significantly less time intensive than MBSR.

Our study, in addition to assessing depression, also evaluated the level of mental wellbeing using a psychometrically valid questionnaire (34) and found higher levels of mental wellbeing among regular meditators. This result was also found by Manocha et al (2009) who suggested that meditation is effective not only in addressing pervasive problems such as work-related stress or burnout, but also in empowering the meditators to achieve a level of enhanced general wellbeing (21). Further, in our study we observed enhanced levels of satisfaction and compassion among regular meditators. In most of the studies, satisfaction per se has not been examined. We assessed the satisfaction with economic status and observed statistically significant differences in satisfaction between meditators and non-meditators. This indicates a higher level of acceptance and non-attachment to changing circumstances, a quality that is embedded in Buddhist foundations and explicitly taught through meditation.

We also examined the differences in the levels of compassion between meditators and non-meditators. In particular, we focused on compassion towards others since we believe this should be a central focus in patient care. Although compassion towards others was shown to be higher among meditators in our study, this was not significant. On the contrary, other studies have reported increased compassion, but in contrast to our study, they have observed increased levels of self-compassion (21-22). Both self-compassion and compassion towards others can be explained by the altruistic perspective practiced in meditation. One plausible explanation for the non-significant difference in compassion may be that compassion, being a cultural characteristic of Sri Lanka, might not have shown significant differences between regular meditators and non-meditators.

Meditation is associated with enhanced mindfulness, reducing attentional biases and increased compassion, which are of utmost importance to those who work in health care. It is simple and can be easily taught, therefore implementation of meditation programmes at workplace do not have to be driven by high cost concerns. Once taught, it can be practised alone. In the presence of heavy workload, the chances of seeking help to improve mental wellbeing are thin among employees of any profession. Therefore, a readily accessible training outside of strict mental health framework, would be most beneficial, particularly if this does not add time commitment and strain to their already overloaded lifestyle.

The strengths of our study are that we introduced a comparatively brief intervention which can be practised by professionals in demanding working environments. The meditation programme we used was easy to practise and required a lower commitment of time than MBSR supporting increased adherence to the programme. One limitation of our study is the lack of randomization into groups. However, meditation by nature is associated with characteristics of an individual such as inherent need or willingness to meditate, readiness to devote time and giving meditation priority among daily activities. Thus, randomized-controlled trials in this context face logistical challenges like high attrition levels among those who do not possess associated characteristics. Therefore, we resorted to descriptive comparative study with those who meditated regularly. This allowed us to compare the mental wellbeing between those inclined toward meditation and those who are not.

A further limitation is that we did not examine downstream effects of improved mental health and wellbeing, such as faster reaction times, diminished anxiety and increased empathy (2), or work performance related outcomes such as creativity, leadership and organizational citizenship (38-39).

\section{Conclusions \& Recommendations}

Our findings suggest that Vipassana informed mindfulness meditation is associated with improved 
mental wellbeing and may have profound practical implications among health care professionals. This method with its simplicity and low-cost approach needs to be tested in other professional groups, in order to increase the generalizability.

\section{Public Health Implications}

Mental wellbeing of individuals, particularly of those who are employed is a concern in many societies including Sri Lanka. This study provides novel insights into a simple low-cost meditation approach to improve mental wellbeing among Sri Lankan health care personnel, and thereby have profound implications in improving the quality of healthcare provided. When health workers are happy and content, the service they provide can be expected to improve in quality and quantity. As mental wellbeing is linked with physical and social wellbeing, improving mental wellbeing will have a positive effect on almost all aspects of health in general. The methods used can be transferable to other occupational categories as well.

\section{Authors Declarations}

Competing interests: Authors declare that they have no conflicts of interests.

Ethics approval and consent to participate: Ethics clearance was obtained from the Ethics Review Committee, Faculty of Medicine, University of Colombo, Sri Lanka. Informed written consent was obtained from all participants prior to the participation.

\section{Funding: None.}

Acknowledgements: Authors wish to acknowledge the cooperation extended by all participants in this study.

Author contributions: All authors read and approved the manuscript. WG was the primary investigator of the study and was involved in developing the concept, statistical analysis, a major contributor in writing the manuscript and provided intellectual content. OJ assisted in obtaining ethical clearance, analysis of data and writing the manuscript. LB was involved in statistical analysis, a major contributor in writing the manuscript and in critically revising the manuscript. IM assisted in obtaining ethical clearance, obtaining data and critically revising the manuscript. CG was involved in developing the concept, statistical analysis and interpretation and critically revising the manuscript.

\section{References}

1. WHO. The World Health Report 2003: Shaping the Future. Geneva: World Health Organization, 2003.

2. Ricard M, Lutz A, Davidson RJ. Mind of the meditator. Scientific American 2014; 311(5): 38-45.

3. Jha AP, Krompinger J, Baime MJ. Mindfulness training modifies subsystems of attention. Cognitive, Affective, \& Behavioral Neuroscience 2007; 7(2): 109-119.

4. Perera H. Buddhism in Sri Lanka: a short history. The Wheel Publication 2008: 1-41.

5. Saisuta VPN. The Buddhist core values and perspectives for protection challenges: faith and protection. High Commissioner's Dialogue Distr: General on Protection Challenges Theme: Faith and Protection, 2012.

6. Khoury B, Lecomte T, Fortin G, Masse M, Therien P, Bouchard V, et al. Mindfulness-based therapy: a comprehensive meta-analysis. Clinical Psychology Review 2013; 33(6): 763-771.

7. Chiesa A \& Serretti A. Mindfulness-based stress reduction for stress management in healthy people: a review and meta-analysis. The Journal of Alternative and Complementary Medicine 2009; 15(5): 593-600.

8. Carlson LE, Speca M, Faris P, Patel KD. One-year prepost intervention follow-up of psychological, immune, endocrine and blood pressure outcomes of mindfulness-based stress reduction (MBSR) in breast and prostate cancer outpatients. Brain, Behaviour and Immunity 2007; 21(8): 1038-1049.

9. Henderson VP, Clemow L, Massion AO, Hurley TG, Druker S, Hébert JR. The effects of mindfulness-based stress reduction on psychosocial outcomes and quality of life in early-stage breast cancer patients: a randomized trial. Breast Cancer Research and Treatment 2012; 131(1): 99-109.

10. Levin AB, Hadgkiss EJ, Weiland TJ, Marck CH, van der Meer DM, Pereira NG, et al. Can meditation influence quality of life, depression, and disease outcome in multiple sclerosis? Findings from a large international web-based study. Behavioural Neurology 2014; 2014. 
11. Peterson LG \& Pbert L. Effectiveness of a meditationbased stress reduction program in the treatment of anxiety disorders. American Journal of Psychiatry 1992; 149(7): 936-943.

12. Hofmann SG, Sawyer AT, Witt AA, Oh D. The effect of mindfulness-based therapy on anxiety and depression: a meta-analytic review. Journal of Consulting and Clinical Psychology 2010; 78(2): 169.

13. Elder C, Nidich S, Moriarty F, Nidich R. Effect of transcendental meditation on employee stress, depression, and burnout: a randomized controlled study. The Permanente Journal 2014; 18(1): 19.

14. Segall SR. Mindfulness and self-development in psychotherapy. Journal of Transpersonal Psychology 2005; 37(2).

15. Goyal M, Singh S, Sibinga EM, Gould NF, RowlandSeymour A, Sharma R, et al. Meditation programs for psychological stress and well-being: a systematic review and meta-analysis. JAMA Internal Medicine 2014; 174(3): 357-368.

16. Malinowski P, Moore AW, Mead BR, Gruber T. Mindful aging: the effects of regular brief mindfulness practice on electrophysiological markers of cognitive and affective processing in older adults. Mindfulness 2017; 8(1): 78-94.

17. Epel E, Daubenmier J, Moskowitz JT, Folkman S, Blackburn E. Can meditation slow rate of cellular aging? Cognitive stress, mindfulness and telomeres. Annals of the New York Academy of Sciences 2009; 1172(1):34-53.

18. Bakker AB \& Demerouti E. The job demands-resources model: state of the art. Journal of Managerial Psychology 2007; 22(3): 309-328.

19. Maslach C, Leiter MP, Jackson SE. Making a significant difference with burnout interventions: researcher and practitioner collaboration. Journal of Organizational Behavior 2012; 33(2): 296-300.

20. Demerouti E, Bakker AB, Nachreiner F, Schaufeli WB. The job demands-resources model of burnout. Journal of Applied Psychology 2001; 86(3): 499.

21. Manocha R, Gordon A, Black D, Malhi G, Seidler R. Using meditation for less stress and better wellbeing: a seminar for GPs. Australian Family Physician 2009; 38(6): 454.

22. Manocha R, Black D, Sarris J, Stough C. Arandomized, controlled trial of meditation for work stress, anxiety and depressed mood in full-time workers. EvidenceBased Complementary and Alternative Medicine 2011;2011.
23. Flook L, Goldberg SB, Pinger L, Bonus K, Davidson RJ. Mindfulness for teachers: a pilot study to assess effects on stress, burnout, and teaching efficacy. Mind, Brain, and Education 2013; 7(3): 182-195.

24. Shapiro SL, Astin JA, Bishop SR, Cordova M. Mindfulness-based stress reduction for health care professionals: results from a randomized trial. International Journal of Stress Management 2005; 12(2): 164.

25. Grover SL, Teo ST, Pick D, Roche M. Mindfulness as a personal resource to reduce work stress in the job demands resources model. Stress and Health 2017; 33(4): 426-436.

26. Bartlett L, Lovell P, Otahal P, Sanderson K. Acceptability, feasibility, and efficacy of a workplace mindfulness program for public sector employees: a pilot randomized controlled trial with informant reports. Mindfulness 2017; 8(3): 639-654.

27. Canter PH. The therapeutic effects of meditation: the conditions treated are stress related, and the evidence is weak. British Medical Journal 2003; 326(7398): 1049.

28. Ospina MB, Bond K, Karkhaneh M, Tjosvold L, Vandermeer B, Liang Y, et al. Meditation practices for health: state of the research. Evidence Report Technology Assessment 2007; 155(155): 1-263.

29. Jamieson SD \& Tuckey MR. Mindfulness interventions in the workplace: a critique of the current state of the literature. Journal of Occupational Health Psychology 2017; 22(2): 180.

30. Crane RS, Brewer J, Feldman C, Kabat-Zinn J, Santorelli S, Williams JMG, et al. What defines mindfulness-based programs? The warp and the weft. Psychological Medicine 2017; 47(6): 990-999.

31. Thatcher C. What is Vipassana? Vipassana Dhura Meditation Society: 2006-2008. Available from: http:/ /www.vipassanadhura.com/whatis.htm.

32. Gunathunga MW. Perfect mental health: an exposition of contemplative neuro-scientific reality of body mind and consciousness. Colombo: Department of Community Medicine, Faculty of Medicine, University of Colombo, 2010.

33. Pocock SJ. Clinical Trials - A Practical Approach. Chichester-New York-Brisbane-Toronto-Singapore: John Wiley \& Sons, 1983.

34. Gunatunga M. Measuring mental health: a new tool and its usefulness. Journal of the College of Community Physicians of Sri Lanka 2012; 15(1). 
35. RadloffLS. The CES-D scale: a self-report depression scale for research in the general population. Applied Psychological Measurement 1977; 1(3): 385-401.

36. Alexander CN, Langer EJ, Newman RI, Chandler HM, Davies JL. Transcendental meditation, mindfulness and longevity: an experimental study with the elderly. Journal of Personality and Social Psychology 1989; 57(6): 950.

37. Baer RA. Mindfulness training as a clinical intervention: a conceptual and empirical review. Clinical
Psychology: Science and Practice 2003; 10(2): $125-$ 143.

38. Hyland PK, Lee RA, Mills MJ. Mindfulness at work: a new approach to improving individual and organizational performance. Industrial and Organizational Psychology 2015; 8(4): 576-602.

39. Good DJ, Lyddy CJ, Glomb TM, Bono JE, Brown KW, Duffy MK, et al. Contemplating mindfulness at work: an integrative review. Journal of Management 2016; 42(1): 114-142. 